\title{
Why there is no evidence for the intrinsic value of non-humans
}

Toby Svoboda

Fairfield University, tsvoboda@fairfield.edu

Follow this and additional works at: https://digitalcommons.fairfield.edu/philosophy-facultypubs Copyright 2011 Indiana University Press. A post-print has been archived here with permission from the copyright holder.

\section{Peer Reviewed}

\section{Repository Citation}

Svoboda, Toby, "Why there is no evidence for the intrinsic value of non-humans" (2011). Philosophy Faculty Publications. 24.

https://digitalcommons.fairfield.edu/philosophy-facultypubs/24

\section{Published Citation}

Svoboda, Toby. "Why there is no evidence for the intrinsic value of non-humans." Ethics \& the Environment 16.2 (2011): 25-36.

This item has been accepted for inclusion in DigitalCommons@Fairfield by an authorized administrator of DigitalCommons@Fairfield. It is brought to you by DigitalCommons@Fairfield with permission from the rightsholder(s) and is protected by copyright and/or related rights. You are free to use this item in any way that is permitted by the copyright and related rights legislation that applies to your use. For other uses, you need to obtain permission from the rights-holder(s) directly, unless additional rights are indicated by a Creative Commons license in the record and/or on the work itself. For more information, please contact digitalcommons@fairfield.edu. 
Why there is no Evidence for the Intrinsic Value of Non-humans (Post-Print Version)

Toby Svoboda, Fairfield University

Published in Ethics \& the Environment 16:2 (2011): 25-36 ${ }^{1}$

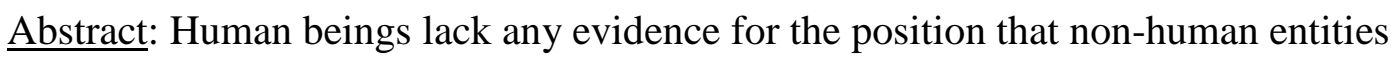
have intrinsic value as a mind-independent property. For any possible world alleged to have such intrinsic value, it is possible to conceive another world that is identical in terms of observable properties but that lacks intrinsic value. Accordingly, inferring the intrinsic value of a non-human from some set of observable properties is unjustified, since the same set of observable properties could exist in an otherwise identical world that lacks intrinsic value. Assuming that humans do not have a faculty of intuition that would allow them to perceive unobservable properties like intrinsic value directly, humans have no evidence for the existence of intrinsic value in non-humans. Hence, the position that some non-humans have intrinsic value is unjustified.

\section{§0: Introduction.}

The position of some environmental ethicists that some non-humans have intrinsic value as a mind-independent property is seriously flawed. This is because human beings lack any evidence for this position and hence are unjustified in holding it. For any possible world that is alleged to have this kind of intrinsic value, it is possible to conceive an

\footnotetext{
${ }^{1}$ This article was published as "Why There is No Evidence for the Intrinsic Value of Non-humans," Ethics and the Environment 16:2 (2011): 25-36. No part of this article may be reproduced, stored in a retrieval system, transmitted, or distributed, in any form, by any means, electronic, mechanical, photographic, or otherwise, without the prior permission of Indiana University Press.
} 
observationally identical world that lacks intrinsic value. Hence, one is not justified in inferring the intrinsic value of some non-human from any set of observable properties, since that same set of properties could just as well exist in a world that lacks intrinsic value. However, since human beings do not have a faculty of intuition that would allow them to perceive unobservable properties directly, they have no good reason to believe that anything has mind-independent intrinsic value. Hence, the position that attributes such intrinsic value to non-humans is unjustified.

The first section of this paper clarifies the concept of mind-independent intrinsic value as exemplified in the work of Holmes Rolston, III. The second section considers objections to the mind-independent intrinsic value of non-humans that have been raised by J. Baird Callicott and Bryan Norton. The third section offers a stronger argument against the mind-independent intrinsic value of non-humans, one that is similar to arguments for humility made by Rae Langton. The fourth section of this paper defends this argument against potential objections. The paper concludes that positions that rely on mindindependent intrinsic value are unjustified and hence should be abandoned.

\section{§1: Rolston’s Conception of Mind-Independent Intrinsic Value.}

Some environmental ethicists hold that some non-human natural entities have mindindependent intrinsic value, which is understood as a property possessed by some entities independently of the beliefs, desires, or attitudes of any actual or possible valuer or knower. Rolston is the best known proponent of this position (Rolston 1982, 1988), although the view is by no means unique to him. Rolston contrasts mind-independent intrinsic value 
with instrumental value (Rolston 1982, 145). An entity has instrumental value only if it is useful as a means to some end other than itself, whereas an entity has mind-independent intrinsic value only if it has value independently of anything else. In short, Rolston conceives of mind-independent intrinsic value as an intrinsic property rather than a relational property, and he claims that some non-human natural entities in fact possess this property.

Rolston’s position implies the view that non-humans who have mind-independent intrinsic value would continue to possess it even in a world that lacked valuers, human or otherwise. This is because intrinsic value is a mind-independent property and hence does not depend on the beliefs, desires, or attitudes of valuers. Further, since Rolston treats intrinsic value as an intrinsic property rather than a relational property, his position implies the view that entities with mind-independent intrinsic value possess it irrespectively of their relations to other entities. Katie McShane likens this to G. E. Moore’s isolation test, according to which something has intrinsic value if and only if its existence would be good even if it were the only entity in the universe (McShane 2007, 49; Moore 1971). McShane further characterizes Rolston’s view as one “according to which claims about the intrinsic value of $X$ are claims about the metaphysical status of $X$ 's value properties” (McShane 2007, 47). She adds that, for Rolston, having the property of mind-independent intrinsic value is akin to having the property of "being made of carbon” (McShane 2007, 49). Just as an entity composed of carbon would continue to be composed of carbon even in a world that lacked scientific investigators, so would an entity with the property of mind-independent intrinsic value continue to possess it even in a world that lacked valuers. Rolston implies 
this when he writes that "intrinsic natural value recognizes value inherent in some natural occasions, without contributory human reference” (Rolston 1982, 145).

Rolston's conception of intrinsic value differs from that of others. For example, Callicott's conception of intrinsic value treats it as a mind-dependent property that requires a valuer to bestow it. According to Callicott, nothing has intrinsic value “in itself,” but a non-human natural entity can be valued by some valuer “for itself” (Callicott 1999). Like Rolston, he contrasts intrinsic value with instrumental value, but he understands each as a way of valuing: “Thus one may value (verb transitive) some things instrumentally... Similarly, one may value (verb transitive) other things intrinsically” (Callicott 2002, 10). Callicott does not accept that non-humans possess intrinsic value as an intrinsic property, because he holds that all value requires a valuer. He claims that humans are the "source" of value, but that non-humans are (or at least can be) the "locus” of value (Callicott 1984, 305).

Despite the fact that both use the term “intrinsic value,” Rolston and Callicott are clearly operating with quite different conceptions of intrinsic value. The objections presented below apply only to mind-independent intrinsic value as conceived by Rolston. That is, this paper critiques only the position that non-human natural entities possess mindindependent intrinsic value as an intrinsic property. Whether Callicott's or another conception of the intrinsic value of non-humans is defensible is beyond the scope of this paper.

§2: Two Objections to Mind-Independent Intrinsic Value. 
Prominent critics of Rolston's position include Callicott and Norton. ${ }^{1}$ Callicott holds that Rolston's position suffers from not offering an alternative to "the metaphysical foundations of modern science,” such as the distinction between primary and secondary qualities (Callicott 1992, 136). Callicott glosses Rolston’s position as follows: “... while the greenness (the qual, not the radiation) of the tree exists only in the mind of the beholder, the moral and aesthetical value of the tree is really out there-no less categorically objective than the electromagnetic waves of precisely 550 nanometers-irrespective of the existence or non-existence of minds and beholders" (Callicott 1992, 138). ${ }^{2}$ According to Callicott, it is implausible to treat value as a primary quality of things themselves while treating color as a secondary quality produced by visual observers. ${ }^{3}$ To make his conception of the intrinsic value of non-humans plausible, Rolston would have to reject these underlying assumptions of modern science, which assumptions make it more plausible to suppose that values are subjective rather than objective properties of entities in themselves.

Norton critiques Rolston for claiming to know what states of affairs are like independently of all “human reference.” As Norton writes, Rolston’s position, if justified, would require “epistemological access to the 'independent' and 'objective’ world outside human experience in order to offer evidence for attributions of characteristics [such as intrinsic value] to objects. If that access is impossible... then Rolston’s theory cannot escape a skeptical collapse” (Norton 1996, 213). ${ }^{4}$ Norton appeals to W. V. O. Quine and Wilfred Sellars, who show that the "representational realism” and "foundationalism” on which Rolston relies are untenable. ${ }^{5}$ Following Quine and Sellars, Norton argues that if Rolston's intrinsic value is “an observable, natural property,” then knowledge of that 
property is already conditioned by human perception and language (Norton 1996, 213). Accordingly, the property of intrinsic value is not known independently of any "human reference," and thus it is not clear that Rolston is justified in claiming that non-humans have intrinsic value as a property independently of such "human reference.” Norton concludes that Rolston "at least owes some account of how we can learn about intrinsic values in nature,” because without such an account it is not clear that there is any good reason to believe that non-human natural entities have mind-independent intrinsic value (Norton 1996, 214). ${ }^{6}$

Despite their criticisms, both Callicott and Norton allow that Rolston might find ways to counter these objections. Callicott notes that Rolston could develop an alternative framework to that of modern science and thereby make it plausible to hold that intrinsic value exists as a mind-independent property. Norton invites Rolston to offer an account that explains how one comes to discover intrinsic value in nature. However, this invitation might be less open than it seems. An anonymous reviewer points out that Norton doubts that Rolston can meet this challenge without making an implausible appeal to intuition. Perhaps like Norton, I hold both that mind-independent intrinsic value could be known only by a faculty of intuition and that humans lack such a faculty. Accordingly, my position might not differ substantially from Norton's. However, the specific objection I raise to the position that non-humans have mind-independent intrinsic value is both different and stronger than either Callicott's or Norton's. This objection holds that human investigators can never have evidence for the existence of mind-independent intrinsic value, because all the observable properties of non-human natural entities could just as well be found in a 
possible world that lacks mind-independent intrinsic value altogether. Hence, even if my conclusion is identical to Norton’s position, my argument offers an original set of reasons in favor of that conclusion. That argument runs as follows.

\section{§3: A Stronger Argument against Mind-Independent Intrinsic Value.}

Imagine two different natural worlds, $A$ and $B$, which are qualitatively identical in every respect, except that some non-human natural entities in $A$ have mind-independent intrinsic value while no non-human natural entity in $B$ has mind-independent intrinsic value. Now imagine a human investigator, Hubert, who is fortunate enough to be able to explore $A$ and $B$ extensively, making careful observations and engaging in various experiences in both worlds. Has Hubert any reason to believe that some entities in $A$ have mind-independent intrinsic value? No, because insofar as he can observe and experience, the entities in $A$ seem qualitatively identical to the entities in $B$ that lack mind-independent intrinsic value. Despite the fact that some entities in $A$ do in fact have mind-independent intrinsic value, Hubert can have no evidence to this effect, because there is nothing observable about the entities in $A$ that would warrant inferring that they have mind-independent intrinsic value. If Hubert were to infer that an entity in $A$ has mind-independent intrinsic value due to some of its observable properties, then by consistency he should accept the view that all entities in $B$ that have these same observable properties also have mind-independent intrinsic value. But this would be mistaken, since no entity in B has mind-independent intrinsic value. This shows that no set of the observable properties of an entity in $A$ is sufficient for it to have 
mind-independent intrinsic value, since there is also an entity in $B$ with an identical set of observable properties that lacks mind-independent intrinsic value.

The same is true for investigations within the actual world, at least for human inquirers. Since humans do not have a faculty of intuition that can perceive metaphysical properties directly, we could only infer the existence of mind-independent intrinsic value from the observable properties of entities. However, we can conceive a world identical to our own in terms of observable properties but which nonetheless lacks mind-independent intrinsic value. Yet we have no way of knowing which of these two worlds we reside in, because both would be observationally identical. This shows that no entity's set of observable properties is sufficient for it to have mind-independent intrinsic value, and therefore we cannot infer legitimately the mind-independent intrinsic value of an entity from its observable properties. Accordingly, it might be the case that some entities have mind-independent intrinsic value in our world, but we have no evidence that they do.

If this argument goes through, then any claim that a non-human natural entity has mind-independent intrinsic value must be unjustified, because none of the observable properties of any entity in our world provide evidence for mind-independent intrinsic value. Norton's request that Rolston offer an account of "how we can learn about intrinsic values in nature” cannot be satisfied (Norton 1996, 214) since the argument shows that human investigators can never have evidence for such value. Hence, Norton and Callicott are right to conclude that mind-independent intrinsic value should not be accepted, although the above thought experiment supports a new and hopefully compelling argument to reach this conclusion. 
This argument is somewhat similar to so-called "arguments for humility," such as that offered by Rae Langton (1998). ${ }^{7}$ Arguments for humility contend that, for various reasons, humans cannot know the intrinsic properties of things. However, such arguments have not previously been directed toward the mind-independent intrinsic value of nonhuman natural entities, and there are other important differences between them and the argument offered above. For example, Langton attributes an argument for humility to Kant, which holds that humans cannot know the intrinsic properties of things-in-themselves. Since humans know things only through their relational properties (e.g., their causal powers), and since these are not reducible to things' intrinsic properties, humans must remain ignorant of the intrinsic properties of things in themselves (Langton 1998, 41-43). Langton’s argument depends a great deal on Kant’s metaphysical and epistemological theses, according to which things-in-themselves are unknowable but nonetheless give rise to objects of experience that humans can know (Kant 2003, 82-83). The argument against mind-independent intrinsic value presented above does not assume that things are unknowable but rather provides reasons why one cannot have evidence for an unobservable property like mind-independent intrinsic value. Perhaps this argument should be classed as an argument for humility, but it is unique both insofar as it is directed toward the mindindependent intrinsic value of non-human natural entities and insofar as it does not make the same assumptions as other arguments for humility. Put schematically, the argument defended in this paper is as follows. 
(1): If humans are justified in holding that some non-human natural entities have mind-independent intrinsic value, then humans possess evidence that some non-human natural entities have mindindependent intrinsic value.

(2): Such evidence must come via a faculty of intuition or via an inference from the observable properties of non-human natural entities.

(3): But this evidence cannot come via intuition, because humans lack such a faculty.

(4): Nor can this evidence come via an inference from observable properties, because those properties could just as well exist in a world that lacked mind-independent intrinsic value.

(5): So humans do not possess evidence that some non-human natural entities have mind-independent intrinsic value.

(6): Thus humans are not justified in holding that some non-human natural entities have mind-independent intrinsic value.

\section{§4: Defending the Argument.}

There are several ways to challenge this argument. First, one could object to (4) by denying that the scenario envisioned by the thought experiment is even possible. That is, one could deny that it is possible for there to be two different worlds that are qualitatively identical save that one has mind-independent intrinsic value while the other lacks it. For example, one might hold this by thinking that a certain set of observable properties is tied 
necessarily to the property of mind-independent intrinsic value, such that an entity that has the former must also have the latter. Moore expresses a view like this. Although he denies that any given moral property is identical to any set of natural properties, he allows that the existence of some set of natural properties might be a sufficient condition for the existence of moral properties. He writes that "if a thing is good (in my sense), then that it is so follows from the fact that it possesses certain natural properties, which are such that from the fact that it is good it does not follow conversely that it has those properties" (Moore 1942, 588). So despite the fact that moral properties are not identical to natural properties, the latter can entail the former (but not necessarily vice versa). According to Moore then, if two different objects are qualitatively identical in their natural properties, then they are also qualitatively identical in their moral properties. Analogously, a defender of mindindependent intrinsic value might hold that the scenario in the thought experiment above is impossible, because it cannot be the case that two objects should have identical sets of observable properties yet only one of them have mind-independent intrinsic value.

However, this objection to (4) is misguided, because the kind of possibility at issue in the thought experiment is logical possibility, not physical or metaphysical possibility. The scenario envisioned in the thought experiment is obviously logically possible, because one can conceive two worlds, $A$ and $B$, that are qualitatively identical in terms of observable properties, and one can further conceive that mind-independent intrinsic value exists in $A$ but not in $B$. Since mind-independent intrinsic value is a particular property, it is not tied to some set of observable properties by any logical necessity—-there is no contradiction involved in conceiving worlds $A$ and $B$. Hence, $A$ and $B$ are both conceivable, 
possible worlds. This means that the thought experiment does envision a possible scenario, and the above objection to (4) does not succeed.

Second, one could hold that human beings do have a faculty of intuition that allows them to perceive mind-independent intrinsic value directly. This would be to challenge the assumption made in (3). Although humans are not justified in inferring mind-independent intrinsic value from any set of observable properties, one could claim that humans directly intuit mind-independent intrinsic value and hence do not need to infer it from what is observed. Rolston himself does not opt for this strategy, and contemporary philosophers in general tend to be skeptical of such a purported faculty. Accordingly, objecting to (3) is unlikely to be attractive to most philosophers. However, if one were to appeal to intuition in this way, one would need to show that humans do have a faculty of intuition, that this faculty would be capable of perceiving mind-independent intrinsic value, and that this intuition is reliable enough to afford actual evidence for mind-independent intrinsic value. These are difficult tasks, and it is far from obvious that they could be accomplished.

Third, one could hold that (2) presents a false dichotomy, because intuition and inference from observable properties are not the only ways humans can acquire evidence about mind-independent intrinsic value. For example, one might contend that mindindependent intrinsic value is itself an observable property that can be known via ordinary observation. On this view, evidence for mind-independent intrinsic value requires neither intuition nor inference. Instead, one could have evidence for mind-independent intrinsic value simply by observing it, perhaps via sensory perceptions. This view also implies again that the thought experiment envisions an impossible scenario. If $A$ and $B$ are qualitatively 
identical in terms of observable properties, and mind-independent intrinsic value is itself an observable property, then either both worlds have such intrinsic value or neither does.

Accordingly, the scenario in which $A$ has mind-independent intrinsic value but $B$ lacks it is not possible.

However, it is implausible to treat mind-independent intrinsic value as an observable property, and few would be willing to make this claim. Humans do not seem to observe such a property in the world. Consider Gilbert Harman’s example of one witnessing two children setting a cat on fire, an action one judges to be morally wrong (Harman 1977, 8). In this case, one observes various non-moral facts (e.g., the children setting the cat on fire and the cat writhing in pain), but one does not observe some moral property such as wrongness. Rather, as Harman argues, it is simpler and more plausible to explain one's moral judgment of the action as wrong in purely psychological terms, i.e. without appealing to any purported mind-independent moral properties (Harman 1977, 8). Even if one contends that there is a mind-independent property of wrongness involved in burning the cat, one has little choice but to treat it as supervenient on non-moral properties, because there is no obvious moral property that is observed in the children's action of burning the cat. The matter is likewise with attributions of mind-independent intrinsic value to non-human natural entities. There is no obvious property of mind-independent intrinsic value observed in non-humans. Either non-human natural entities have mind-independent intrinsic value as a non-observable property or they lack mind-independent intrinsic value altogether. In either case, the position that non-human natural entities have mindindependent intrinsic value loses, because then the above argument goes through. 


\section{§5: Closing Remarks.}

This paper has argued that positions recognizing the mind-independent intrinsic value of non-humans are unjustified because humans can have no evidence in favor of that position. Accordingly, such positions are deeply flawed and should be abandoned. This does not entail that non-human natural entities lack intrinsic value under some other conception, as long as that conception does not involve making claims about properties for which one can have no evidence. Accordingly, environmental ethicists might still defend the value of non-human natural entities, but appeals to mind-independent intrinsic value should be left behind.

\section{Acknowledgments.}

Earlier versions of this paper were presented at the Political Ecology and Environmental Philosophy conference at Colby College (April 2010) and a Public Research Colloquium at Penn State University (November 2010). I would like to thank participants of both events for very helpful feedback. I would also like to thank David Agler for careful and insightful comments on a draft of this paper.

\footnotetext{
${ }^{1}$ For a defense of Rolston against both critics, see Preston (1998).

${ }^{2}$ For Rolston's example of greenness, see Rolston (1988, 116-117).

${ }^{3}$ Callicott suggests that "postmodern" science, particularly quantum mechanics, offers an alternative to the "metaphysical foundations" of modern science, and he draws upon quantum mechanics to develop his own conception of intrinsic value. See Callicott (1992, 138-43).

${ }^{4}$ See also Rolston $(1994,167-202)$.
} 
${ }^{5}$ Norton directs his readers to Quine (1951) and Sellars (1956).

${ }^{6}$ See also Norton (1992).

${ }^{7}$ See also Whittle (2006, 461-97). 


\section{$\underline{\text { References. }}$}

Callicott, J. Baird. 1984. "Non-anthropocentric Value Theory and Environmental Ethics.” American Philosophical Quarterly 21: 299-309.

---. 1992. “Rolston on Intrinsic Value: A Deconstruction.” Environmental Ethics 14 (2): 129-144.

---. 1999. “Intrinsic Value in Nature: A Metaethical Analysis.” In Callicott, Beyond the Land Ethic: More Essays in Environmental Philosophy, 239-61. Albany: State University of New York Press.

---. 2002. “The Pragmatic Power and Promise of Theoretical Environmental Ethics: Forging a New Discourse.” Environmental Values 11: 3-25.

Harman, Gilbert. 1977. The Nature of Morality: An Introduction to Ethics. New York: Oxford University Press.

Kant, Immanuel. 1781/1787 (2003). Critique of Pure Reason. Translated by Norman Kemp Smith. New York: Palgrave MacMillan.

Langton, Rae. 1998. Kantian Humility: Our Ignorance of Things in Themselves. Oxford: Clarendon Press.

McShane, Katie. 2007. “Why Environmental Ethics Shouldn’t Give Up on Intrinsic Value.” Environmental Ethics 29 (1): 43-61.

Moore, G. E. 1942. “A Reply to My Critics.” In The Philosophy of G. E. Moore, edited by Paul Schilpp, 533-688. Evanston: Northwestern University Press.

---. 1971. Principia Ethica. Cambridge: Cambridge University Press.

Norton, Bryan. 1992. “Epistemology and Environmental Values.” The Monist 75 (2): 208226. 
---. 1996. “Conserving Natural Value.” Review of Conserving Natural Value, by Holmes Rolston III. Environmental Ethics 18 (2): 213-4.

Preston, Christopher. 1998. “Epistemology and Intrinsic Values: Norton and Callicott’s Critiques of Rolston.” Environmental Ethics 20 (4), 409-428.

Quine, W. V. O. 1951. From a Logical Point of View. Cambridge: Harvard University Press.

Rolston III, Holmes. 1982. “Are Values in Nature Subjective or Objective?” Environmental Ethics 4 (2), 125-151.

---. 1988. Environmental Ethics: Duties to and Values in the Natural World Philadelphia: Temple University Press.

---. 1994. Conserving Natural Value. New York: Columbia University Press.

Sellars, Wilfred. 1956. “Empiricism and the Philosophy of Mind.” In Minnesota Studies in the Philosophy of Science, Volume 1: The Foundations of Science and the Concepts of Psychology and Psychoanalysis, Herbert Feigl and Michael Scriven eds. Minneapolis: University of Minnesota Press, 253-329

Whittle, Ann. 2006. “On an Argument for Humility.” Philosophical Studies 130 (3), 461497. 